\title{
Structural Performance of Broken Ceramic Tiles As Partial Replacement of Coarse Aggregates In
}

\author{
Concrete
}

\author{
Adeniran Jolaade Adeala and Lawrence Ademola Omisande \\ Civil Engineering Department, Federal Polytechnic Ilaro Ogun State, Nigeria
}

\begin{abstract}
In an attempt to curb the menace associated with the collection and disposal of construction wastes, the study investigated the characteristics of broken ceramic tiles concrete graded levels : $0 \%, 5 \%, 10 \%, 15 \%$ and $20 \%$ of broken tiles wastes with maximum size of $19 \mathrm{~mm}$ generated from construction sites used to substitute conventional coarse aggregate in the production of 1:2:4 mix concrete, at constant water-cement ratio of 0.5 cast in sets of sixteen (16) each in $150 \mathrm{~mm} \times 150 \mathrm{~mm} \times$ $150 \mathrm{~mm}$ moulds. The resulting concrete cubes cured for 28 days were tested for absorption, compressive strength and workability in accordance with BSEN 12350-3: 1983 and BS8110: 1997. The result showed that the compressive strength values: $28.25 \mathrm{~N} / \mathrm{mm}^{2}$, $27.44 \mathrm{~N} / \mathrm{mm}^{2}, 26.88 \mathrm{~N} / \mathrm{mm}^{2}$ and $26.33 \mathrm{~N} / \mathrm{mm}^{2}$ at $5 \%, 10 \%, 15 \%$ and $20 \%$ respectively although decreases with increase in percentage replacement is comparable with that of a normal concrete up to $20 \%$ replacement. Workability and absorption properties of the broken tiles concrete also exhibited the same trend with that of compressive strength. The study concluded that BTC at 28 days possesses strikingly similar characteristics with normal concrete up to $20 \%$ replacement.
\end{abstract}

Keywords: Broken Ceramic Tiles, Workability, Compressive Strength, Water Absorption.

\section{INTRODUCTION}

$\mathrm{C}$ oncrete is a building and structural material obtained by mixing cement, aggregates (fine \& coarse), water, and admixture (if necessary)[1]. Concrete is used more than any other man made material on this planet. It is a low cost material and can be used for the construction of any type of structure. Aggregates which are one of the materials used in making concrete are chemically inert solid particles of selected sizes, held together by the hardened cement paste, which acts as the binder to aggregates. Aggregates that can be natural gravel, crushed rock or an artificially prepared heavy or light weight material, are available in various shapes, sizes and qualities that may range from fine sand to large, coarse rocky materials. Because cement remains the most expensive ingredient in making a concrete, it is desirable to minimize the quantity of cement and maximize the quantity of aggregate used in concrete production. In a normal concrete, 75 to $85 \%$ of the volume of concrete is aggregate that makes the cost of concrete relatively low. The choice of aggregate is determined by the proposed use and importance of structure, environmental conditions to which the structure will be exposed and the availability of aggregate within an economical distance. Owing to liberalization, globalization and privatization, the construction of important infrastructure projects like, buildings, roads, airports etc. in Nigeria is increasing year after year. Such developmental activities consume large quantity of precious natural resources. This leads to faster depletion of natural resources on one side and manifold increase in the cost of construction of structures on the other side pose severe problem for the construction sector. This problem is very severe in Nigeria.

\subsection{Background of Study}

In view of this, researchers have started searching for suitable other viable alternative materials which could be used either as a substitute or as a partial replacement to the conventional ingredients of concrete so that the existing natural resources could be saved to the possible extent and could be made available for the future generation[9]

As part of efforts to make efficient use of industrial wastes available materials, this study was carried out to investigate the influence of partial replacement of conventional coarse aggregates by broken ceramic tiles on the workability, density and compressive strength of concrete as well as to assess the suitability of broken tiles concrete as a structural materials. Research carried out on compressive strength, water absorption and modulus of elasticity of concrete made with ceramic aggregate. Crushed ceramic blocks were used as coarse aggregate in concrete fabrication. Specific density of aggregate was 2630 to $2310 \mathrm{~kg} / \mathrm{m}^{3}$ for 0 to $100 \%$ replacement. Up to the replacement of $20 \%$, Compression resistance and modulus of elasticity was equivalent with conventional concrete .Different industrial and agricultural waste materials such as fly ash, quarry dust, groundnut shell ash, broken glass waste, waste from ceramic, waste aggregate from demolition of structures etc, have been adopted as a viable substitute or partially material to the conventional materials in concrete.[10] suggested that the compressive, splitting tensile and flexural strengths of ceramic waste coarse aggregate were decreased by $3.8,18.2$ and $6 \%$ respectively when compared to conventional concrete.

\section{MATERIALS AND METHODS}

This research work entails both Field and laboratory work. The Field work required sourcing for aggregates (Sharp sand 
and granite) and broken ceramic tiles. The waste ceramic broken tiles were collected from construction sites in Federal Polytechnic Ilaro and Ilaro community in ogun state, Nigeria.The laboratory experiments were carried out in Civil Engineering Concrete Laboratory Federal Polytechnic Ilaro, Ogun State. Crushed granite used for the study was of size $19 \mathrm{~mm}$. It was obtained from the quarry located at Abeokuta Ogun State, Nigeria. The broken tiles used were sourced from the tiles sellers at Ilaro, Ogun State of Nigeria. Sharp sand used was obtained from Sand sellers in Ilaro. Dangote brand of ordinary Portland cement produced at the cement factory located at Ibese plant Ilaro, Ogun State of Nigeria as obtained from the market at Ilaro in Ogun State was used in the concrete production. Water supplied by The Federal Polytechnic Ilaro was used in mixing the materials. The water looked clean and was free from any visible impurities. It conformed to the requirements of [8].Particle size distribution was carried out on aggregates both fine and coarse aggregate in line with [3].The mix design ratio of 1:2:4 with watercement ratio of 0.5 was adopted. Workability of fresh concrete was carried out in accordance to.[4], water absorption and compression test on cube concrete were carried as stipulated in [5], [2] and [6] respectively. Concrete cubes were cured and compressive were carried out on cured cubes at 7, 14, 21 and 28days and water absorption was carried out on 28 days cube concrete for both conventional and modified concrete.

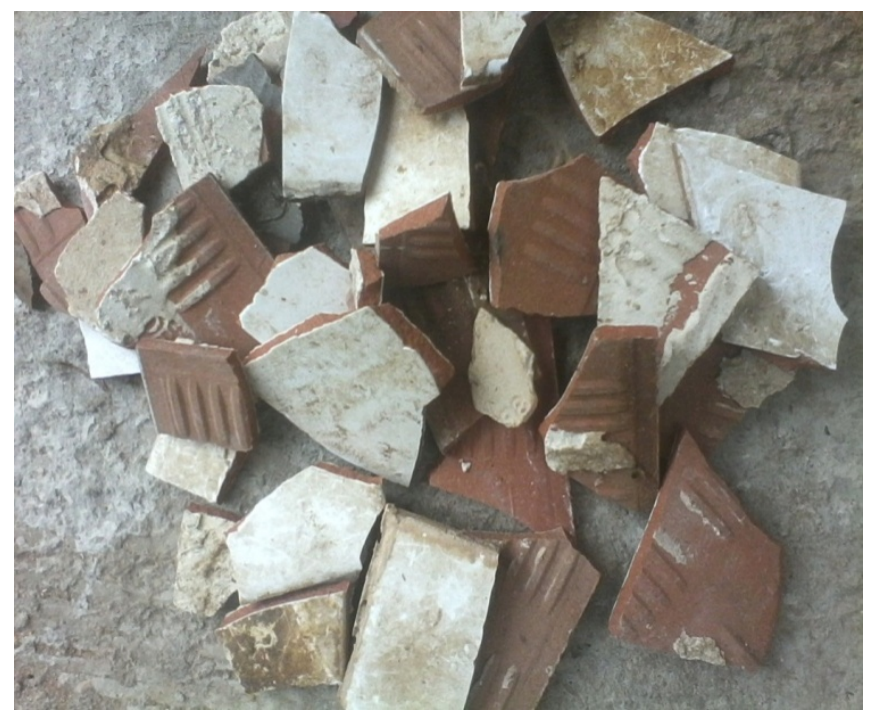

Fig. 1: Broken ceramic tiles

Table 1: Batch Weight of materials $(\mathrm{kg})$ for each mix

\begin{tabular}{|c|c|c|c|c|c|}
\hline & $\begin{array}{c}\text { Mix I } \\
(0 \%)\end{array}$ & $\begin{array}{c}\text { Mix I } \\
(5 \%)\end{array}$ & $\begin{array}{c}\text { Mix II } \\
(10 \%)\end{array}$ & $\begin{array}{c}\text { Mix III } \\
(15 \%)\end{array}$ & $\begin{array}{c}\text { Mix IV } \\
(20 \%)\end{array}$ \\
\hline Cement & 18 & 18 & 18 & 18 & 18 \\
\hline F.A & 36 & 36 & 36 & 36 & 36 \\
\hline C.A & 72 & 68.4 & 64.8 & 61.2 & 57.6 \\
\hline BCT & 0 & 3.6 & 7.2 & 10.8 & 14.4 \\
\hline Water & 9 & 8.75 & 8.50 & 8.25 & 8.0 \\
\hline
\end{tabular}

\section{RESULTS AND DISCUSSIONS}

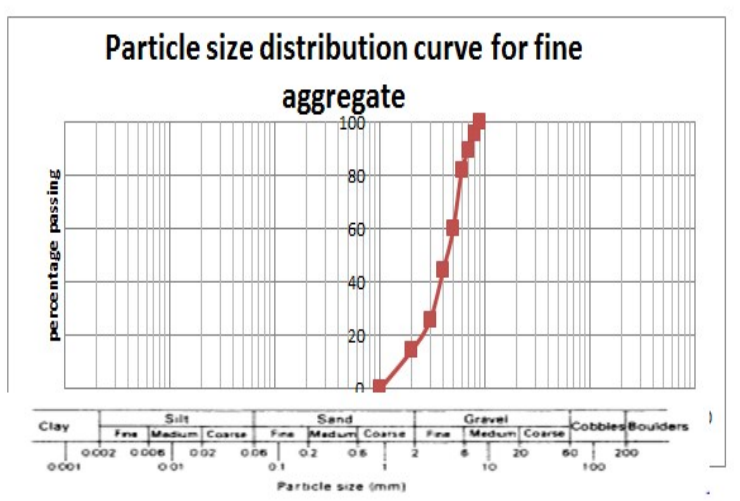

Fig. 2: Particle size distribution curve for fine aggregates

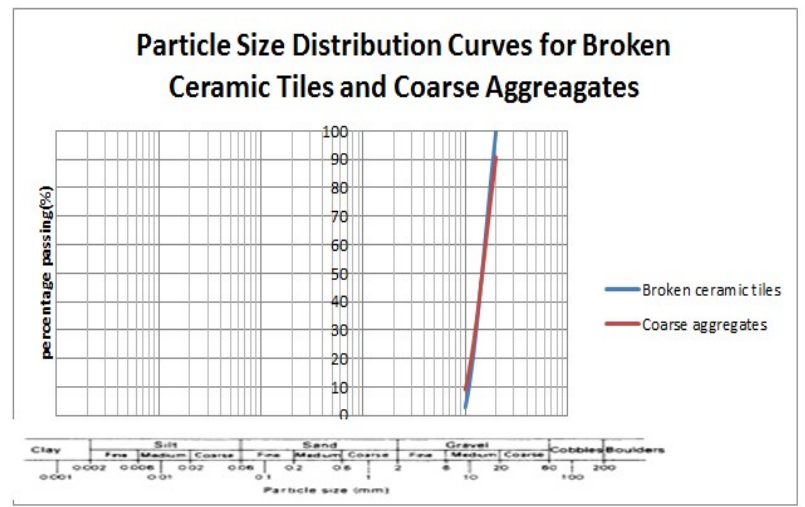

Fig .3: Particle size distribution curve for broken ceramic tiles and coarse aggregates

It was observed that all the aggregates were well graded in accordance to BS1377-2. (1990).

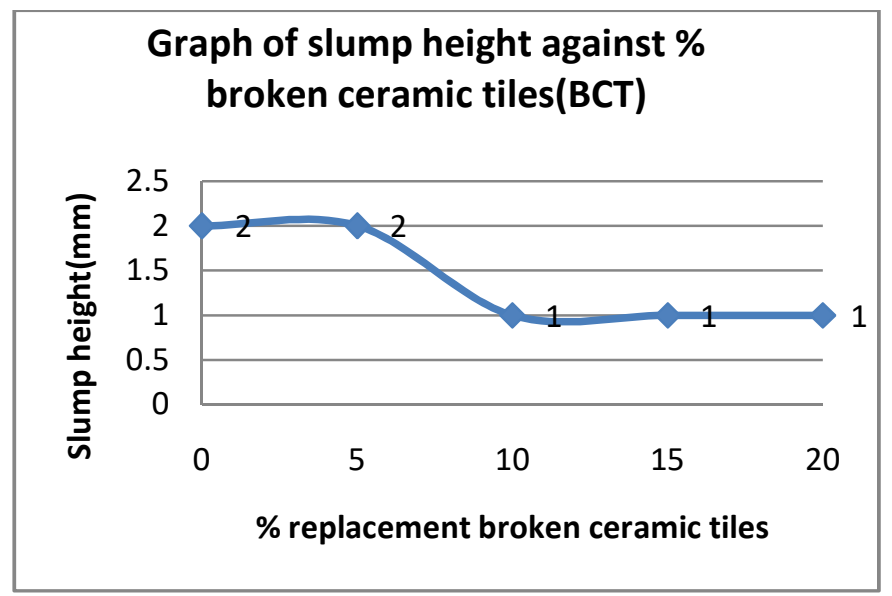

Fig .4: Graph of slump against \% broken ceramic tiles concrete specimen. 
At $5 \%$ replacement of coarse aggregate with broken ceramic tiles the slump height was $2 \mathrm{~mm}$ as that of control, on reaching $10 \%$ substitute the fresh concrete has slump of $1 \mathrm{~mm}$ which then maintained the same at $15 \%$ and up to $20 \%$. It was observed that higher the broken ceramic tiles in concrete the less workable the concrete this is due to the fact tiles cannot absorb water because smooth and glazy it was made of.

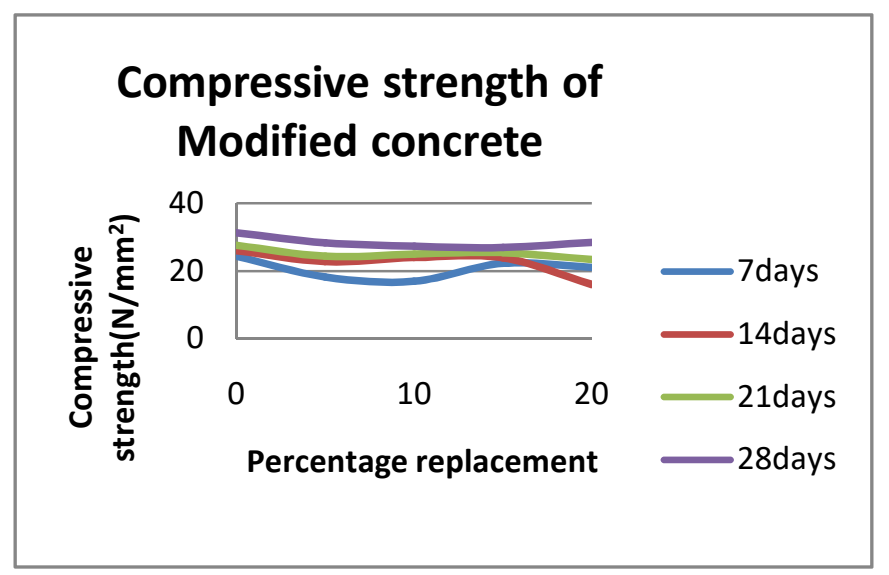

Fig. 5: Compressive strength development of modified concrete with curing days.

There was improvement in the strength of modified concrete as the curing days and percentage replacement of broken tiles increases as shown in fig. 5 above. In fig. 6 it was observed that higher the broken ceramic tiles in concrete the lesser the compressive strength. Normal concrete produced compressive strength of $31.26 \mathrm{~N} / \mathrm{mm}^{2}$.Also it was deduced that broken ceramic tiles concrete at $5 \%, 10 \%, 15 \%$ and $20 \%$ produced compressive Strength of $28.25 \mathrm{~N} / \mathrm{mm}^{2}, 27.23 \mathrm{~N} / \mathrm{mm}^{2}$, $26.88 \mathrm{~N} / \mathrm{mm}^{2} \& 26.34 \mathrm{~N} / \mathrm{mm}^{2}$ respectively. According to BS 8110-1-1997, stated that for normal aggregate concrete, the least compressive strength for $1: 2: 4 \mathrm{mix}$ design ratio is $25 \mathrm{~N} / \mathrm{mm}^{2}$, which means coarse aggregate (granite of $19 / 20 \mathrm{~mm}$ size) can be substituted between 5 and $20 \%$ of broken ceramic glazy tiles to have minimum compressive strength of $25 \mathrm{~N} / \mathrm{mm}^{2}$ which can also be used for reinforced structures such as building.

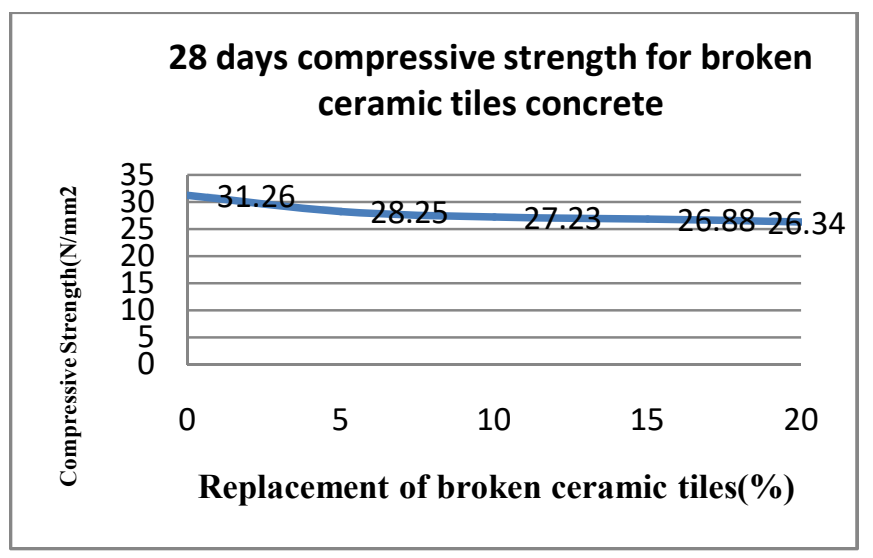

Fig .6: Compressive Strength development at 28 days against broken ceramic tiles $(\%)$

\subsection{Statistical Modeling}

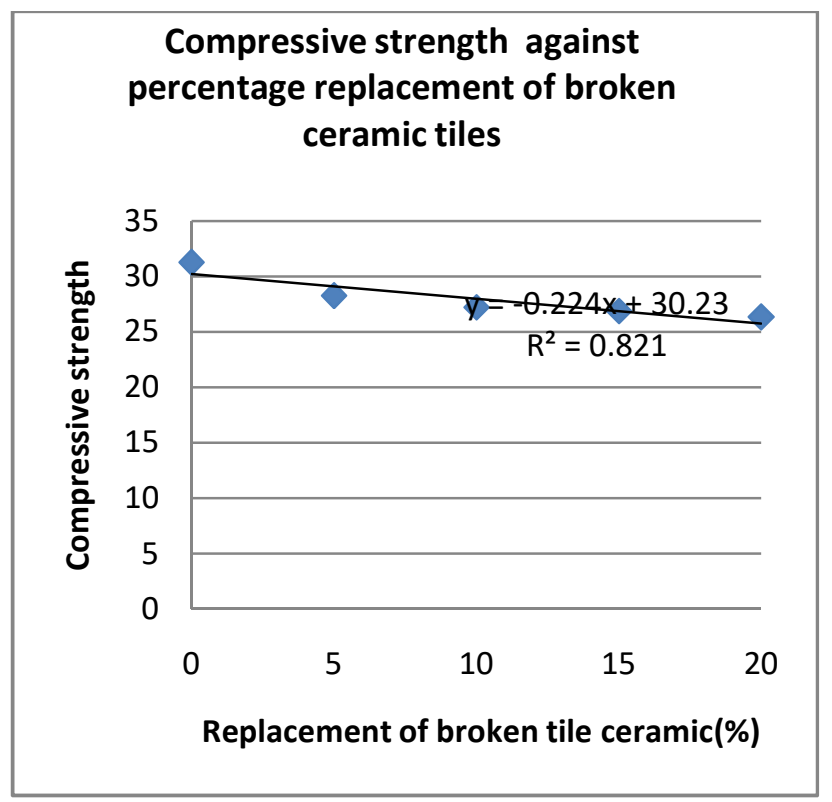

Fig.7: Regression analysis showing relationship between compressive strength at 28 days and percentage replacement of broken ceramic tiles.

It was observed that the relationship has been obtained using polynomial regression analysis as $\mathrm{F}_{\mathrm{st}}=-0.224 \mathrm{x}+30.234$ and there was strong correlation between compressive strength and substitution percentage of broken ceramic tiles.To determine percentage of broken ceramic tiles that will produce compressive strength of $25 \mathrm{~N} / \mathrm{mm}^{2}$.

$25=-0.224 x+30.234$

$\mathrm{X}=23.4 \%$

It requires that $23.4 \%$ of broken ceramic tiles in concrete will produce compressive strength of $25 \mathrm{~N} / \mathrm{mm}^{2}$.

Table 2: Water absorption for 28 days concrete.

\begin{tabular}{|c|c|}
\hline Replacement (\%) & Density $\left(\mathrm{Kg} / \mathrm{m}^{3}\right)$ \\
\hline 0 & 2405 \\
\hline 5 & 2412 \\
\hline 10 & 2423 \\
\hline 15 & 2445 \\
\hline 20 & 2473 \\
\hline
\end{tabular}

The density of control specimen is $2405 \mathrm{Kg} / \mathrm{m}^{3}$ and at $5 \%$ it was $2412 \mathrm{Kg} / \mathrm{m}^{3}$, at $10 \%$ replacement it was $2423 \mathrm{~kg} / \mathrm{m}^{3}$ and rise to $2445 \mathrm{Kg} / \mathrm{m}^{3}$ at $15 \%$ and at $20 \%$ substitution it was taken up to $2473 \mathrm{Kg} / \mathrm{m}^{3}$.

Table 3: Water Absorption of 28days curing concrete

\begin{tabular}{|c|c|}
\hline Replacement (\%) & Absorption (\%) \\
\hline 0 & 0.9 \\
\hline 5 & 0.66 \\
\hline
\end{tabular}




\begin{tabular}{|c|c|}
\hline 10 & 1.0 \\
\hline 15 & 2.2 \\
\hline 20 & 2.8 \\
\hline
\end{tabular}

The water absorption from table. 3 at $0 \%$ was 0.9 and on replacement of $5 \% \mathrm{BCT}$, it dropped to $0.66 \%$ when it reached $10 \%$ rate was 1.0 and also increased to $2.2 \%$ at $15 \%$ substitute and finally accelerate to $2.8 \%$ at $20 \%$ substitute. It was observed that $20 \%$ broken tiles concrete has the highest water absorption rate of $2.8 \%$ and $5 \%$ BTC has the lowest water absorption rate of $0.66 \%$. It was shown that increase in broken ceramic tiles led to increase in water absorption of concrete.

\subsection{Cost Implication}

Quantity saved

$5 \%$ broken ceramic tiles $=3.6 / 126 \times 100=2.86 \%$

$10 \%$ broken ceramic tiles $=7.2 / 126 \times 100=5.71 \%$

$15 \%$ broken ceramic tiles $=10.8 / 126 \times 100=8.57 \%$

$20 \%$ broken ceramic tiles $=14.4 / 126 \times 100=11.43 \%$

Cost saved

$5 \%$ broken ceramic tiles $=2.86 / 100 \times 1224=\# 35.01$

$10 \%$ broken ceramic tiles $=5.71 / 100 \times 1224=\# 69.89$

$15 \%$ broken ceramic tiles $=8.57 / 100 \times 1224=\# 104.90$

$20 \%$ broken ceramic tiles $=11.43 / 100 \times 1224=\# 139.90$

Based on the cost implication above, if 5 tons of $19 \mathrm{~mm}$ granite cost \# 15,000 and 20\% of broken tiles is used then the quantity of granite that will be saved is $\frac{20}{100} * 5=1$ tons of granite will be saved.

Likewise for the cost $\frac{20}{100} * 15000=\# 3000$ will be saved. Therefore using broken ceramic tiles at $20 \%$ substitute of coarse aggregate is economically viable.

\section{CONCLUSIONS}

All the modified fresh concrete had true slump lied within $1 \mathrm{~mm}$ and $2 \mathrm{~mm}$.Compressive strengths of modified concrete from $5 \%$ substitute up to $20 \%$ were more than $25 \mathrm{~N} / \mathrm{mm}^{2}$ and this show that such concrete with broken tiles has better potential than conventional concrete with the same mix design ratio of 1:2:4 for 28 days compressive strength. Broken ceramic concrete falls within the standard acceptable range of conventional concrete $2300-2500 \mathrm{Kg} / \mathrm{m}^{3}$ which show the same behavior of normal concrete. The modified concrete satisfy the condition of a good concrete which its water absorption varies from 0.89 to $3 \%$ in accordance concrete Society, United Kingdom .In Conclusion, recycling of broken ceramic waste tiles can be used up to $20 \%$ replacement of coarse aggregates in the production of concrete in both developing and developed countries.

\section{ACKNOWDGEMENTS}

I appreciate the efforts of Mr. Adeyinka A.O, Technician in charge of concrete laboratory in Federal Polytechnic Ilaro and Emmanuel Odueme 2015/2016 set of Civil Engineering for data collection Federal Polytechnic Ilaro Ogun State, Nigeria.

\section{REFERENCES}

[1] Balogun, M.O (2009). Introduction to Properties of Construction Materials. Ibadan: All Deals Investment Company Limited Nigeria.

[2] BS 813-2.(1995), Determination of Water Absorption of Concrete. London: British Standards Institution.

[3] BS 1377-2.(1990), Sieve Analysis of Dry Sample. London: British Standard Institute.

[4] BS 1881-102.(1983), Methods of Determination of Slumps. London: British Standards Institute.

[5] BS 1881-114.(1983), Methods of Determination of Density. London: British Standards Institute.

[6] BS1881-116.(1983), Method for Determination of Compressive Strength of Concrete. London: British Standards Institute.

[7] BS 1881. (1986). Methods of testing concrete. London: British Standards Institute.

[8] BS 3148.(1980).The requirement of water for concrete mixing. London: British standard Institute.

[9] K.A Mujedu,I.O Lamidi \& D.O Ayelabola. (2014). An Investaigation On the Suitability of the Broken Tiles as Coarse Aggregates in Concrete Production. The International Journal Of Engineering And Science, 35-41.

[10] Senthamarai R (2005): Use of waste ceramic tiles for road pavement subgrade International Journal of Innovative Research in Science, Engineering and Technology 12088- 12815

[11] Singh, P. \&.Rakesh K.S (2015). Utilization of Waste Ceramic Tiles As Coarse Aggreagates In Concrete. Journal of Multidisciplinary Engineering Science and Technology, 32943300 . 